\title{
DIPLOMACIA PÚBLICA PRIVADA: EL FIn DEL MONOPOLIO PÚBLICO SOBRE LAS RELACIONES INTERחACIONALES
}

\section{Private public diplomacy. The end of public hegemony over international relations}

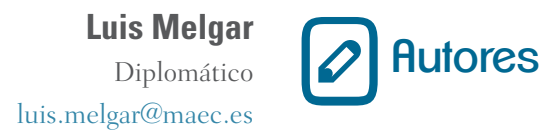

FIRMA INVITADA

Desde sus inicios en los años sesenta del siglo XX, la diplomacia pública ha contemplado la participación de actores no estatales en las relaciones internacionales, tales como empresas multinacionales, medios de comunicación, universidades, think tanks o incluso la propia opinión pública.

En el contexto actual de pérdida de soberanía de los Estados, proliferación de actores en las relaciones internacionales y adelgazamiento del sector público en las economías occidentales, existe una tendencia creciente a la privatización de las relaciones internacionales.

Esta tendencia se refleja en la aparición de dos conceptos: el polilateralismo y la nueva diplomacia pública, que trata de las relaciones directas entre opiniones públicas de distintos países, sin que sea necesaria la intervención de los Estados.

Podríamos encontrarnos ante el nacimiento de un paradigma completamente nuevo: una diplomacia pública privada que partiría de la renuncia definitiva de los Estados a su monopolio tradicional sobre las relaciones internacionales a favor del sector privado.

Diplomacia, Diplomacia Pública, Diplomacia Pública Privada, Diplomacia Coorporativa, Diplomacia Cultural

Q Key words Diplomacy, Public Diplomacy, Private Public Diplomacy, Corporate Diplomacy, Cultural Diplomacy 
Since the concept of public diplomacy was developed in the 1960', its practitioners have accepted that sovereign states are not the only actors of international relations. On the contrary, there is a wide range of actors in the International Society, such as corporations, media, universities, think tanks. Even global public opinion could be considered an actor by itself.

In the actual context where states are starting to loose their sovereignty and the public sector is becoming proportionally less important in Western economies, there is a growing tendency towards privatization of international relations.

This tendency reflects on two concepts: polylateralism and new public diplomacy, which consists in direct relations among different countries public opinions, with no participation of sovereign states.

We could be witnessing a completely new model: a private public diplomacy that would be based on a sovereign states definitive withdrawal from their monopoly on international relations in favour of the private sector.

\section{Introducción}

En el año 1870 a.C., el faraón Sesostris III avanzó la frontera sur de Egipto de la primera catarata del Nilo a la segunda, y construyó allí una fortificación que controlase principalmente el tráfico comercial (Galán Allué, 1995). Allí mandó levantar una estela que rezaba lo siguiente:

Frontera sur establecida para prevenir que los nubios la traspasen navegando río abajo o por tierra, excepto aquel nubio que venga a comerciar como comisionado. Con éstos hay que actuar correctamente, sin dejar que ninguna otra barca de nubios pase río abajo.

La mayoría de los historiadores modernos consideran que el Antiguo Egipto era una civilización introvertida, aislada de sus vecinos por factores geográficos y culturales. Tan sólo salía de sus fronteras con objetivos bélicos. Pero la realidad es muy otra. Desde los inicios mismos de su historia, el Antiguo Egipto mantuvo contactos pacíficos con pueblos extranjeros cuya finalidad principal era, a la luz de los documentos que nos han llegado, el intercambio de productos.

Con el paso del tiempo, estos primeros contactos pacíficos se fueron regularizando y formalizando. Las misiones comerciales nubias de tiempos de Sesostris III derivaron, bajo el reinado de la reina Hatsepsut, en la creación de la figura del comisionado real. Éste tenía la misión de representar a la reina, repitiendo sus palabras y argumentos y actuando de acuerdo con los intereses del monarca.

En el Antiguo Egipto, los primeros diplomáticos fueron comerciantes privados, hombres de negocios que arriesgaban vida y hacienda para hacer fortuna más allá de las fronteras de su país. Fue sólo con el transcurrir de los siglos, cuando la corte del faraón se hizo más grande y disponía de una auténtica legión de escribas, sacerdotes y eunucos a su servicio -funcionarios, en definitiva- que se inventó la figura del diplomático profesional, al servicio del monarca, en este caso el comisionado real. Y es que en la dilatada historia egipcia, siempre hubo una constante: el interés comercial.

En el siglo XXI, la sociedad internacional parece estar viviendo el proceso contrario. Aunque tradicionalmente las relaciones internacionales han sido monopolio exclusivo de los Estados, ya en los años sesenta del siglo XX surgió el concepto de diplomacia pública (Melgar, 2010), que desde un inicio contempló la participación de actores no estatales en las relaciones inter- 
nacionales, tales como medios de comunicación, universidades, think tanks e incluso la propia opinión pública. Si la diplomacia tradicional se concibe como las relaciones directas de Estado a Estado, la diplomacia pública se centra en las relaciones entre los Estados y las opiniones públicas extranjeras.

En el contexto actual de pérdida de soberanía de los Estados, proliferación de actores de las relaciones internacionales y adelgazamiento del sector público en las economías occidentales, existe una tendencia creciente a la privatización de las relaciones internacionales. Esta tendencia afecta de modo especialmente intenso a la diplomacia pública.

Aunque es cierto que los Estados son cada vez más conscientes de la importancia de la diplomacia pública, que abarca sectores como la comunicación, la diplomacia cultural o la diplomacia económica, también lo es que desde principios del siglo XXI está pujando con fuerza el concepto de "nueva diplomacia pública" (Melissen, 2005), en la cual el Estado empieza a desaparecer de la ecuación. La nueva diplomacia pública trata de las relaciones directas entre opiniones públicas de distintos países, sin que sea necesaria la intervención de los Estados.

Esta tendencia podría desembocar en algo completamente nuevo: una diplomacia pública privada $^{1}$ que partiría de la renuncia definitiva de los Estados a su monopolio tradicional sobre las relaciones internacionales a favor del sector privado. Se abre por tanto un interesante campo de trabajo para los expertos en relaciones internacionales y, concretamente, en diplomacia pública, que pasarían a ser imprescindibles en el ámbito empresarial.

\section{El polilateralismo y la nueva diplomacia pública}

Los teóricos de las relaciones internacionales coinciden en que, en el siglo XXI, la sociedad internacional no puede entenderse únicamente en términos de relaciones entre Estados sobe$\operatorname{ranos}^{2}$, sino que se debe tener en cuenta un espectro más amplio de interacciones y de formas de diálogo que implican a un número cada vez más elevado de actores: organizaciones internacionales, empresas multinacionales, ONGs, medios de comunicación, opinión pública, etc.

Sin embargo, a menudo no se ha prestado la suficiente atención a las consecuencias que este cambio de paradigma en la sociedad internacional tiene para la práctica profesional de la diplomacia. Hasta fechas muy recientes, el ejercicio de la diplomacia ha sido un monopolio exclusivo de los Estados soberanos (Vilariño, 2007). El Derecho Internacional estudia cuáles son los órganos del Estado, centrales y periféricos, encargados de las relaciones internacionales, como son los Jefes de Estado y de Gobierno, los ministros de Asuntos Exteriores y las redes de embajadas y consulados repartidas por el mundo. Pero si los Estados ya no son los únicos actores de la sociedad internacional, es evidente que el resto de actores habrán de dotarse de órganos semejantes, encargados del ejercicio de las relaciones internacionales.

Este escenario configura una sociedad internacional donde las relaciones van más allá de lo bilateral o multilateral que, en cualquier caso, tienen como centro de gravedad al Estado. Surge

1 En 1989, el profesor Alain Rubin llamó la atención al entonces recién elegido presidente George Bush sobre las potencialidades de la diplomacia privada.

2 Ya en 1956 el profesor Paul Reuter afirmó que la Sociedad Internacional contemporánea no podía ser entendida como una mera yuxtaposición de Estados soberanos. La doctrina ha seguido evolucionando en este mismo sentido hasta el punto de que ya nadie habla del Estado ni como actor único de la Sociedad Internacional ni como sujeto en exclusiva del Derecho Internacional público.
Existe una

tendencia creciente a la privatización de las relaciones internacionales 
así el conceto de polilateralismo (Wiseman, 1999), donde las relaciones se desarrollan entre el Estado y el resto de actores no estatales, o por qué no, entre estos actores no estatales entre sí, sin necesidad de intervención alguna del Estado.

La nueva diplomacia pública que mencionábamos más arriba parte de este concepto de polilateralismo para hacer hincapié en los nuevos retos de una sociedad internacional con cada vez mayor número de actores, como puede ser la aparición de comunicaciones instantáneas o la creciente confusión entre asuntos internos e internacionales debida a la globalización. En último término, la nueva diplomacia pública trata de la relación de opiniones públicas entre sí, prescindiendo cada vez más de la acción del Estado.

El concepto original de nueva diplomacia pública pertenece a la diálectica del FCO británico ${ }^{3}$, y parte de la idea de que la diplomacia de hoy se mueve en un nuevo entorno caracterizado por la implementación cada vez mayor de la democracia, que, no obstante, convive con incipientes movimientos populistas. Esto hace que la opinión pública global, que existe gracias a la instanteneidad de las comunicaciones y a la revolución tecnológica ${ }^{4}$, sea cada vez más importante en términos de relaciones internacionales. Además, la globalización económica ha aumentado la competencia comercial y turística entre los países en un contexto donde a menudo las decisiones están descentralizadas. Las amenazas a la seguridad se conciben de modo global, como el terrorismo internacional o el cambio climático.

Todo ello hace que los gobiernos no puedan controlar tan fácilmente la información como lo hacían durante la Guerra Fría. Por lo que la diplomacia pública tiene que basarse en la coherencia entre la imagen-país que se intenta exportar y la política exterior llevada a cabo. Para ello, la mejor estrategia consiste en construir interrelaciones de confianza que abarquen a un número lo más grande posible de actores, teniendo en cuenta que, en un mundo globalizado, la frontera entre la política interior y la exterior se torna cada vez más difusa.

Junto a los efectos de este nuevo contexto internacional, debe tenerse en cuenta la experiencia práctica obtenida a raíz de los ataques del 11-S en los EE.UU. y su respuesta en forma de guerra contra el terror. Los problemas a los que ha tenido que enfrentarse la diplomacia pública americana a raíz de la guerra de Irak, tanto en los países islámicos como en el resto del mundo, han obligado reflexionar sobre el concepto mismo de diplomacia pública. Desde esta perspectiva, la nueva diplomacia pública, con su estrategia de red, sería la única arma diplomática para luchar contra organizaciones terroristas como al-Qaeda, que se configura como una red de círculos concéntricos que opera a través de células independientes coordinadas de una forma muy difusa (Cull, 2009).

De este modo, se ve a la diplomacia pública como un instrumento que puede ser de utilidad tanto para afrontar las relaciones entre Estados occidentales posmodernos como entre éstos y los que pertenecen a otros ámbitos culturales. Sin embargo, para que ello sea eficaz, los países occidentales deben aceptar que se trata de un diálogo entre iguales, aunque con legítimas diferencias de valores.

3 Como ya se ha dicho, este concepto ha sido ampliamente analizado por autores como J. Melissen, pero también por B. Hocking y M. Leonard.

4 La opinión pública global ha sido estudiada desde múltiples perspectivas, como la propia de las relaciones internacionales (Hayden, 2012) o desde la óptica de las ciencias de la información (Alberto 2008).

La nueva diplomacia pública trata de la relación de diferentes opiniones públicas entre sí 
La nueva diplomacia pública partiría, por tanto, de un enfoque de redes que pueden ser de dos tipos (Rana, 2011):

» Las mega-redes, formadas por la amplia gama de organismos internacionales, con la ONU como centro. También se incluyen redes políticas transnacionales en las que intervienen representantes de los gobiernos, tecnócratas, representantes corporativos, grupos de presión y ONGs. Estas mega-redes son la evolución natural de la diplomacia tradicional, ya que incluyen a los diferentes actores de las relaciones internacionales.

» Las micro-redes son el aspecto más novedoso de la nueva diplomacia pública, y se identifican en gran medida por conceptos como la multi-track diplomacy o la diplomacia civil. Se trata de pautas de interacción social que pueden gestionar la diplomacia pública en un país desde la Embajada o el instituto cultural en el exterior, para incluir a cooperantes, líderes de opinión, periodistas, centros religiosos, etc.

Este nuevo concepto de gestión de la imagen-país ofrece la ventaja de la despolitización, lo que lleva a la creación de políticas de Estado, en vez de programas que pueden cambiar según el signo político del gobierno. Sin embargo, también tiene un enorme reto: la coordinación. Una acción tan descentralizada bien puede convertirse en una miríada de acciones contradictorias que acaben por distorsionar, difuminar y hasta pervertir la imagen del país, por lo que resulta imprescindible un importante esfuerzo de coordinación.

Abundando en el concepto de polilateralismo, uno de los errores más corrientes es atribuir el ejercicio de la diplomacia pública únicamente a actores estatales. Las entidades supra o subestatales, tales como las Naciones Unidas, la Unión Europea o los gobiernos regionales y locales, al igual que los actores no estatales como empresas multinacionales y ONGs, llevan a cabo poderosas estrategias de diplomacia pública.

Las ONGs han venido demostrando su enorme capacidad para influir sobre la opinión pública internacional. Organizaciones como Greenpeace o Amnistía Internacional se han convertido en actores globales que, en múltiples ocasiones, trabajan codo con codo con los mismos gobiernos que antaño las observaban con desconfianza. La historia reciente está repleta de ejemplos donde la llamada sociedad civil transnacional ha unido sus esfuerzos a ciertos Estados y al propio sistema de las Naciones Unidas para conseguir objetivos comunes, como la Convención de Ottawa de 1997 sobre la erradicación de minas antipersona o el establecimiento del Tribunal Penal Internacional.

Las empresas multinacionales tampoco se encuentran al margen de este proceso. Conforme se asienta la idea de la responsabilidad social corporativa (RSC), las estrategias de diplomacia pública de las grandes compañías se han ido volviendo más sofisticadas. Casos como el de Deloitte China, que inició hace unos años un proyecto en la provincia de Yunnan para mejorar los estándares de calidad de vida a través de la educación básica, son cada vez más habituales. En Guinea Ecuatorial5, empresas petroleras como Marathon Oil y Noble Energy financian por completo el único proyecto de protección del medio ambiente que existe en el país: el Bioko Biodiversity Protection Program.

5 Todas las referencias a Guinea Ecuatorial las conozco por experiencia directa obtenida durante el desempeño de mis funciones como Segunda Jefatura de la Embajada de España en Malabo.

Las entidades

supra o

subestatales llevan a cabo poderosas estrategias de diplomacia pública 
En definitiva, la diplomacia pública actual trabaja en un entorno de red donde unos actores pueden colaborar e influir sobre otros de forma interconectada, en vez del modelo estatocéntrico que data de la Paz de Westfalia. En este entorno de red carateriazado por la globalización, las estrategias de comunicación pública son la principal herramienta de trabajo.

\section{Comunicación pública y medios de comunicación: el punto de partida}

La comunicación es sin duda uno de los elementos clave de la diplomacia pública, hasta el punto de que a menudo se confunden y se intercambian ambos conceptos (Alberto Pérez, 2008). Pero no siempre ha sido así.

Hasta hace pocos años, la comunicación institucional, los public affairs, estaban radicalmente separados de la diplomacia pública: mientras la comunicación institucional tenía como objetivo la información a la opinión pública interna por parte de las instituciones, la diplomacia pública era un ejercicio de gestión de la imagen-país por parte de esas mismas autoridades, pero orientado a un público - o públicos- extranjeros. En la actualidad, es evidente que ambas están tan interrelacionadas que es imposible diferenciarlas, ya que cualquier mensaje público alcanza indistintamente a públicos nacionales y extranjeros. Hoy, toda comunicación institucional tiene un elemento de diplomacia pública, sea cual sea la institución que la genere: desde el Ministerio de Asuntos Exteriores al Ayuntamiento de un pequeño municipio. Por otro lado, todo ejercicio de diplomacia pública ha de contener, en mayor o menor medida, un elemento de comunicación.

A menudo, la diplomacia pública se trata como un flujo de información en una sola dirección: del Estado a la opinión pública extranjera. Craso error, ya que una estrategia de diplomacia pública que se produce en forma de monólogo corre el riesgo de convertirse en propaganda. La diplomacia pública, incluso considerada desde una perspectiva únicamente estatocéntrica, ha de revestir siempre la forma de un diálogo, de ahí que la recopilación de información sea uno de los elementos constitutivos tradicionales de la diplomacia pública. Desgraciadamente, en muchos ministerios de Asuntos Exteriores los departamentos de comunicación siguen relegados a dos únicas funciones: diseminar información y coordinar las relaciones con la prensa.

Sin embargo, la nueva diplomacia pública va un paso más allá al considerar por primera vez la comunicación no institucional, es decir, la que brota de actores privados como ONGs, empresas, think tanks, universidades, individuos y, por supuesto, la propia actividad de los medios de comunicación. En este caso ya no podríamos hablar de monólogo ni de diálogo: sería más bien una suerte de conversación global donde los Estados se verían obligados a compartir escena con el resto de actores de las relaciones internacionales.

Para matizar este concepto de conversación global, es preciso insistir sobre un hecho: la diplomacia pública no es en absoluto un ejercicio de altruismo, sino un instrumento para participar en el proceso de toma de decisiones en la sociedad internacional. La diplomacia pública sirve para perseguir un enorme rango de objetivos, entre los cuales la promoción de valores (democráticos, humanísticos o de otra índole) no es más que una pequeña parte. La diplomacia pública es una herramienta para conseguir los objetivos de la política exterior de los Estados, para incrementar el flujo comercial, para atraer inversiones o para incrementar las ventas de una determinada empresa. Sin embargo, por su propia naturaleza acaba generando una externalidad positiva que es su contribución a la formación de una opinión pública global.
Una estrategia de diplomacia pública en forma de monólogo puede convertirse en propaganda 
Desde este punto de vista, cualquier actor interesado en participar en este proceso global de toma de decisiones debería contar con especialistas en relaciones internacionales y, concretamente, en diplomacia pública.

Pongamos algunos ejemplos. Poco después de su creación, en 1961, Amnistía Internacional comenzó a enviar llamamientos para impedir la ejecución de presos de conciencia (Clark, 2001). Con el tiempo, su trabajo sobre la pena de muerte se fue ampliando. La organización comenzó en 1977 su campaña global contra la pena de muerte, una campaña que parte de la necesidad de concienciar a la opinión pública internacional sobre esta cuestión. Pero la influencia de Amnistía Internacional no se limita únicamente a la opinión pública, sino que va más allá: a los partidos políticos, a las autoridades, a los medios de comunicación, a las organizaciones internacionales, a las empresas. Para llevar a cabo su labor, los responsables de esta campaña han de relacionarse con organizaciones tan dispares como el Consejo de Europa, responsable del Protocolo número 13 a la Convención Europea de Derechos Humanos cuyo objetivo es la abolición completa de la pena de muerte, la Cruz Roja Internacional o la Organización de Estados Americanos. Han de tener contactos con activistas, medios de comunicación y autoridades en países donde la pena de muerte es una realidad, para así tener acceso a los casos concretos que más tarde habrán de denunciar. Han de ser, en definitiva, auténticos especialistas en relaciones internacionales y, cómo no, en diplomacia pública.

En la década de los 90, la firma Nike protagonizó un escándalo de relaciones públicas ${ }^{6}$ debido a las condiciones de trabajo en las fábricas extranjeras que producían los artículos de la compañía, que se convirtió en blanco de protestas contra de los peligros de la globalización. El tema salió a la luz en 1996, cuando la revista Life publicó un artículo con la foto de un niño cosiendo un balón de fútbol de Nike.

Al principio, los responsables de la empresa argumentaron que, como Nike no era dueña de las fábricas, no era responsable de las condiciones de trabajo o seguridad. Dos años más tarde, el fundador de la compañía, Phil Knight, prometió en un discurso en Washington erradicar el trabajo infantil. Nike hizo público el nombre y la ubicación de sus plantas, el primer minorista importante en hacerlo. Mejoró la calidad del aire para los trabajadores al usar pegamento a base de agua en lugar de adhesivos a base de petróleo para fijar las suelas de los zapatos. También envió decenas de personas a puestos permanentes en los países donde producía sus artículos, y trabajó con las fábricas para encontrar ahorros de costos y mejorar el trato de los trabajadores. En 2005, Nike había comenzado a ganar elogios de los mismos activistas que previamente lo criticaron severamente. En definitiva, orquestó una campaña de diplomacia pública que fue más allá de la propia política de imagen para entablar relación con organizaciones internacionales, ONGs e incluso con los propios Estados donde se estaban produciendo los bienes. Quizá la crisis de Nike en los años 90 fue uno de los detonantes de la aparición del concepto de responsabilidad social corporativa.

Los propios medios de comunicación se ven envueltos con mucha frecuencia en este proceso global de toma decisiones; no en vano constituyen el famoso cuarto poder que configura y da forma a la opinión pública internacional. Los ejemplos son innumerables: un determinado periódico o canal de TV adopta una línea editorial respecto a un régimen concreto. Esta línea editorial conforma un estado de la opinión pública que, a la larga, afecta a la línea de política exterior que se adopta
Los medios de comunicación dan forma a la opinión pública internacional

6 El caso de Nike se estudia en la mayoría de las escuelas de negocios al hablar de cómo afrontar crisis de comunicación corporativa. Existe abundante literatura al respecto, pero en el manual editado por Millar y Heath en 2003 se aporta una perspectiva comparada. 
respecto a ese régimen. Sin ir más lejos, el difunto presidente venezolano Hugo Chávez arremetía con frecuencia contra la "poderosa campaña mediática internacional contra Venezuela", cargando las tintas de modo especialmente virulento contra el grupo español Prisa y contra The New York Times. Es indudable que los conglomerados mediáticos son jugadores de primer nivel en el proceso global de toma de decisiones, por lo que los responsables de marcar las líneas editoriales han de ser, por fuerza, expertos en relaciones internacionales y diplomacia pública.

\section{La diplomacia cultural: potencialidades de un partenariado público-privado ${ }^{7}$}

Si la comunicación pública es una de las herramientas por excelencia de la diplomacia pública, ya sea estatal o de otros actores, la diplomacia cultural es sin duda el instrumento más antiguo de la diplomacia pública. Mucho antes del nacimiento del Estado-nación, griegos y romanos utilizaban magistralmente la influencia cultural como instrumento de poder. El gran logro de Alejandro Magno no fue conquistar un imperio de carácter efímero, sino dar el pistoletazo de salida al helenismo, una oleada de influencia cultural griega que ha dado forma a la civilización occidental de nuestros días.

Del mismo modo, la romanización fue el instrumento de asimilación por excelencia del Imperio Romano. Una vez que las legiones y los generales habían cumplido su misión conquistando un territorio, llegaba un nuevo ejército de ingenieros, maestros, sacerdotes, comerciantes y artesanos que fusionaban la cultura autóctona con la que venía de Roma. Ya en esos tiempos, había una doble forma de diplomacia cultural: por un lado la que venía del propio Imperio, que exigía el uso del latín, el respeto a las leyes, la obediencia a los dioses, y por otro, la diplomacia pública que llevaban a cabo día a día los ciudadanos particulares, los artistas, los maestros.

El debate entre los dos modelos, el público y el privado, continúa hoy día y centra la reflexión sobre el futuro de esta disciplina.

La financiación pública de la diplomacia cultural tiene la ventaja de liberar a las organizaciones (museos, teatros, artistas, etc.) de la a menudo difícil tarea de recaudar fondos, y normalmente proporciona un mayor margen de creatividad a los programadores. El teatro experimental, por ejemplo, no suele caracterizarse por su enorme éxito de taquilla y difícilmente podría sostenerse sin implicación pública. Sin embargo, este apoyo gubernamental puede generar una cierta "funcionarización” de los operadores culturales, que al contar con un apoyo público garantizado, no tendrían en cuenta factores como la rentabilidad o el grado de aceptación por parte del público.

El modelo privado tiene dos vertientes distintas pero complementarias. La primera de ellas es la consideración de las industrias culturales y creativas (ICC) como un agente económico más dentro de una economía de mercado, por mucho que en su conjunto generen una externalidad positiva como es el aumento del nivel cultural medio de la población. Desde ese punto de vista, las ICC deben atenerse a criterios de rentabilidad, o en el peor de los casos, tenerlos muy en cuenta. La
El debate entre los modelos público y privado de diplomacia cultural continúa

7 El modelo español de diplomacia cultural aparece ampliamente citado en la publicación de la Escuela Diplomática "Retos de nuestra acción exterior: Diplomacia Pública y Marca España". Como puede comprobarse, la presencia del sector público en la diplomacia cultural española es predominante, partiendo del modelo de subvenciones y terminando en la titularidad estatal de la mayoría de las entidades consagradas a la acción cultural exterior. Sin embargo, son varias las iniciativas que permiten intuir un avance hacia un partenariado público-privado, como puede ser el propio proyecto Marca España, que promueve la búsqueda de financiación privada para la diplomacia pública, o la tan discutida reforma de la Ley de Fundaciones. 
principal ventaja de este sistema es la enorme competencia entre las ICC y los propios artistas, que se ven obligados a mejorar constantemente para sobrevivir. En el lado negativo, hay que considerar que los índices de consumo no siempre son un criterio de calidad para los bienes culturales.

Una segunda vertiente tendría como eje de gravedad la filantropía de los agentes privados, el llamado mecenazgo. Es indudable que la filantropía existe per se en la sociedad, aunque en dosis relativamente escasas. Es papel de los poderes públicos crear un conjunto de beneficios fiscales que faciliten la aparición de mecenas, aunque las propias instituciones culturales (museos, teatros, etc.) también pueden fomentar este fenómeno mediante ventajas de índole fundamentalmente social. El gran beneficio de este sistema es que genera una sana competencia entre ICC, instituciones y artistas en general sin hacerles enteramente dependientes de los albures del mercado, aunque hay que reconocer que favorece casi exclusivamente a instituciones y artistas de renombre, y normalmente, no a manifestaciones culturales experimentales.

Recientemente se ha hablado mucho del partenariado público-privado para crear un modelo mixto de diplomacia cultural. Es cierto que este modelo sería, teóricamente, el mejor de todos, ya que sería el más equilibrado en cuanto a beneficios y desventajas. Sin embargo, hay que reconocer que este partenariado aún no ha terminado de dar sus frutos ${ }^{8}$, y es difícil encontrar instituciones culturales donde el patrocinio público-privado coexista en proporciones similares y relativa armonía. Pero ello no significa ni mucho menos que no sea el camino adecuado.

En efecto, el nuevo contexto en el que se desarrolla el intercambio cultural transnacional requiere un nuevo enfoque, tanto de los actores públicos como de los privados. En Estados Unidos, pero también en Europa, los gobiernos están reduciendo su aportación económica a la política cultural, por lo que la responsabilidad de la misma recae cada vez más sobre el sector privado. Por el contrario, en regiones emergentes como Asia o Iberoamérica, o en diferente sentido en los países del Golfo Pérsico, se está experimentando una especie de edad de oro de la acción cultural del Estado gracias a un boom económico que permite a los gobiernos invertir grandes cantidades de dinero en esta política.

En los países occidentales en general, y en España en particular, es evidente que la diplomacia cultural debe optar por un modelo de coexistencia entre lo público y lo privado. El equilibrio aún está por definir, pero es evidente que habrá de mantener las dosis justas de gestión cultural, relaciones internacionales y sostenibilidad económica.

Tal y como se está perfilando, este modelo cuenta con una dosis más que considerable de acción cultural, entendida como el conjunto de actuaciones de los poderes públicos dirigidas a difundir la cultura de un país en el exterior. Por propia definición, la acción cultural cae íntegramente en un modelo público que, en el caso español, adopta ciertas peculiaridades.

La primera de estas peculiaridades es la proliferación de actores ${ }^{9}$, todos ellos de naturaleza pública: pensemos en el Instituto Cervantes, la red de centros culturales dependientes de la Agencia Española de Cooperación Internacional y Desarrollo, los consejeros culturales de las

8 En 2012 se celebró en Salzburgo un Seminario Global sobre el nuevo papel del sector privado en la diplomacia cultural donde se suscitaron cuestiones interesantes, como la auténtica razón de ser de la diplomacia cultural más allá del interés de los Estados (Szántó, 2012).

9 En mi primer estudio sobre diplomacia pública en 2010 ya llamé la atención sobre el reto que suponía la proliferación de actores en nuestro modelo de diplomacia pública. Recordemos que la iniciativa Marca España no ha sido sino un intento de racionalizar esta proliferación que tiene su origen en un contexto presupuestario muy distinto al que vivimos en la actualidad.

\section{La diplomacia cultural debe optar por un modelo de coexistencia entre lo público y 10 privado}


Embajadas, Acción Cultural Exterior, la red de Casas dependientes del Ministerio de Asuntos Exteriores y Cooperación... sin olvidar la acción cultural que llevan a cabo otros departamentos ministeriales, las Comunidades Autónomas e incluso los Ayuntamientos. Una auténtica miríada de actores que configuran un sistema en red potencialmente muy efectivo pero también poco óptimo financieramente hablando, ya que los recursos cada vez más escasos de la Administración se ven muy diluidos.

Otra característica singular de la acción cultural española es la ausencia de funcionarización. Al no existir un cuerpo de gestores culturales del Estado, las principales instituciones encargadas de la acción cultural recurren al personal contratado laboral, que proviene casi en exclusiva del ámbito de la gestión cultural, sin tener en cuenta la dosis de relaciones internacionales que conlleva la acción cultural exterior. Es evidente que no se puede programar el Instituto Cervantes de Rabat como si fuera un espacio vanguardista ubicado en Barcelona o que la gestión del Centro Cultural de España en Bata, Guinea Ecuatorial, difiere mucho del de la Casa de la Cultura de Burriana.

En acción cultural exterior, hay que ser capaz de adaptar la programación cultural al guión de la política exterior española, y no sólo eso, sino también de encontrar la forma de utilizar la cultura como un instrumento al servicio de los intereses y valores que el Estado español ha decidido defender. Es necesario definir a quién va dirigida esta acción cultural: ¿̇a las élites culturales, políticas o empresariales? ¿A la ciudadanía en general? ¿A la población marginal como elemento de cooperación cultural? Por otro lado, la acción cultural exterior española habrá de adaptarse a los distintos ámbitos geográficos, lo cual significa también adaptar el mensaje a los distintos públicos.

Hay que ser capaz de adaptar la programación cultural al guión de la política exterior

El fenómeno del polilateralismo, que ya hemos definido antes, también afecta a la acción cultural, de modo que las fronteras entre lo interior y lo exterior son cada vez más borrosas. La programación del Museo del Prado, ¿es política cultural interna o acción cultural exterior, si tenemos en cuenta que es uno de los lugares más visitados por los millones de turistas que cada año llegan a nuestro país? Desde ese punto de vista, instrumentos aparentemente internos, como las subvenciones a las ICC, tienen poderosos efectos más allá de nuestras fronteras. Algo similar ocurre con lo que se ha llamado la creación de esos clusters: aglomeraciones de ICC que se convierten por derecho propio en focos culturales a nivel global. Basta con citar algunos ejemplos: Hollywood para la industria del cine, Broadway para los musicales, el West End para el teatro o Milán para la moda. Aunque los operadores son caso exclusivamente privados, existe un elemento público en la promoción y creación de estos clusters.

La política cultural del estado se enfrenta, en fin, a un dilema difícil de solventar. ¿Qué cultura debe promocionar?, ¿la plural o mayoritaria?, ¿la alta cultura, o la cultura popular?, ¿moderna o tradicional?, ¿agresiva o integradora? Tópicos, ¿sí o no? Si tenemos en cuenta que la cultura es un modo de participar en esa conversación global que conduce a la toma de decisiones, es evidente que la respuesta a estas preguntas no debe basarse en factores únicamente culturales, sino también políticos y de relaciones internacionales.

Más allá del papel del Estado, no podemos olvidar la función que desempeñan las ICC en sí, en tanto que agentes económicos que toman sus propias decisiones. Desde el punto de vista internacional, las ICC tienen dos prioridades: la internacionalización y la exportación. Veamos algunos ejemplos.

Hoy día, nadie duda de la existencia de un espacio literario homogéneo en al ámbito iberoamericano, que une literariamente hablando a la inmensa mayoría de países de habla hispana. Este 
hecho funciona como un elemento integrador de valor incalculable. Los hispanohablantes sentimos igual de nuestro a Camilo José Cela que a Gabriel García Márquez, a Rubén Darío que a Pablo Neruda, y eso crea un sentimiento de comunidad difícil de lograr por otros medios. Sería un error pensar que este espacio literario homogéneo ha surgido espontáneamente, o como consecuencia inevitable de la existencia de un mismo idioma. Hay un elemento comercial indudable: las grandes editoriales han apostado por crear empresas transnacionales en los distintos países iberoamericanos y por facilitar el tráfico de libros entre las dos orillas del Atlántico. Existe también un ingrediente político. Cuando una editorial española desea vender sus libros de texto para que se utilicen en los colegios de Guinea Ecuatorial, necesita tener en cuenta el complejo equilibrio que mantienen las relaciones bilaterales entre los dos países... pero a su vez, el uso de libros de texto españoles en los colegios ecuatoguineanos tiene una consecuencia política, por lo que ello significa de promoción de valores como la democracia o la igualdad de género. En ese espacio literario iberoamericano, los tres elementos se conjugan con igual importancia: lo económico, lo político y lo propiamente educativo o cultural.

Pensemos en Miami, cluster de la industria discográfica latina de ambas orillas del Atlántico. ¿A qué obedece su existencia? Sin duda a la coexistencia de factores políticos como la emigración cubana, económicos, facilitados por las autoridades de Florida y, por supuesto, puramente culturales.

Más allá de la acción cultural del Estado y de las propias ICC, existen otros elementos de la diplomacia cultural donde el triple equilibrio economía-cultura-relaciones internacionales queda de manifiesto. Pensemos por un momento en la educación. Desde un punto de vista público, Francia ha conseguido convertir el Liceo Francés en un auténtico instrumento de poder del Estado, al lograr que gran parte de las élites intelectuales del mundo entero se hayan formado de niños en el sistema educativo francés. EE.UU. comienza a hacer lo mismo con una visión más privada a través, por ejemplo, de la creación de American Universities en distintos lugares del planeta. En la ciudad que se está construyendo como futura capital de Guinea Ecuatorial, Oyala, se está poniendo en marcha la American University for Central Africa, un proyecto docente respaldado por la Universidad de Boston que tendrá como lengua principal el inglés... y esto, en el único país de África donde se habla castellano. El papel de colegios, universidades y otras instituciones educativas para aumentar el poder blando de un Estado no es ni mucho menos desdeñable, y una vez más, se deben tener en cuenta los tres elementos: económicos, de relaciones internacionales $\mathrm{y}$, por supuesto, educativos.

Por último, es imposible dejar de mencionar el elemento decisivo de la diplomacia cultural española, el buque emblemático de la imagen de nuestro país en el exterior: nuestro idioma, el español. Aunque la creación del Instituto Cervantes es tardía si se compara con la de otras instituciones semejantes en países vecinos, hay que decir que su labor ha sido muy encomiable y se ha caracterizado por un enorme éxito. Las Embajadas españolas siempre reciben la misma petición de las autoridades locales: por favor, abrid un Instituto Cervantes. Y es que, sin lugar a dudas, el español es un valor en alza. No significa ello que no haya margen para la mejora. Hace décadas que se habla del potencial que supone para el poder blando de España el que haya un número cada vez mayor de hispanohablantes en EE.UU. ${ }^{10}$, y sin embargo, nadie ha sido capaz

10 Por ejemplo Alvar, M. (1991): El español de las dos orillas, Madrid, Mapfre. 
de hallar la fórmula para que ese potencial revierta en un beneficio tangible para los españoles, ya sea desde un punto de económico o político.

El aspecto económico de este triángulo de competencias puede estudiarse a través del concepto de diplomacia económica.

\section{Las empresas multinacionales como actores globales: diplomacia corporativa}

Al hablar de diplomacia económica, inmediatamente nos viene a la mente el concepto de diplomacia comercial ${ }^{11}$ : la acción que llevan a cabo determinados organismos públicos o semipúblicos (ICEX, oficinas comerciales, cámaras de comercio, etc.) para promover la internacionalización de las empresas españolas o el aumento de sus exportaciones. Existe una abundante doctrina sobre la materia y se trata, qué duda cabe, de un ámbito profesional amplio para los especialistas en relaciones internacionales y, especialmente, en comercio exterior.

En Europa, y más si cabe en España, la diplomacia comercial es en la práctica un monopolio público. Esto no tendría por qué ser así. En el contexto ya descrito de disminución relativa del peso del sector público en la economía, existe un nicho de negocio indudable para consultorías especializadas en internacionalización de empresas, por no hablar de bufetes de abogados que, al mismo tiempo, pueden asesorar a sus clientes sobre la distinta legislación mercantil de los países a dónde desean expandirse.

Sin embargo, un ámbito académico tradicionalmente olvidado en España, a pesar de su auge en otros países como Estados Unidos, es el de la diplomacia corporativa. En efecto, la nueva diplomacia del siglo XXI tiene un carácter cada vez más polilateral, y requiere por tanto la estrecha colaboración de diplomáticos tradicionales, agentes de la cooperación, militares, ONGs, medios de comunicación, individuos y, por supuesto, las grandes empresas multinacionales. En este sentido, la diplomacia corporativa sería el papel que desempeñan las compañías transnacionales en la sociedad internacional.

Hoy en día, las grandes empresas ya no pueden considerarse como pertenecientes a uno u otro Estado, ya que su influencia va más allá del país donde está ubicada su sede corporativa o fiscal. Pensemos por ejemplo en Iberia, la antigua compañía de bandera y titularidad pública cuya imagen estaba estrechamente ligada con la de nuestro país. Tras los sucesivos procesos de privatización y fusión con otras compañías que ha experimentado, Iberia ya no es una empresa española, ni británica, ni argentina, ni de ningún otro país. Al carecer de un accionista claramente mayoritario, Iberia es, por definición, una empresa transnacional cuyos intereses no están claramente alineados con los de ningún Estado, incluida por supuesto España. Sin embargo, la paradoja se produce porque en muchos lugares del mundo la imagen de Iberia sigue estrechamente ligada a la de España, y las acciones de una repercuten sobre la otra y viceversa de forma inevitable.

Las grandes empresas constituyen un nuevo tipo de jugador en el proceso global de toma de decisiones (Li, 2013). El caso de Repsol YPF y Argentina ${ }^{12}$ es un ejemplo paradigmático de di-

11 Vicente Montes y Antonio Camuñas explican magistralmente la diferencia entre diplomacia comercial y diplomacia corporativa en "Retos de nuestra acción exterior...", de la Colección Escuela Diplomática.

12 (Fernández, 2012). Otro caso paradigmático que se estudia en las escuelas de negocios de todo el mundo. 
plomacia corporativa: dos Estados se ven envueltos en un conflicto diplomático cuyo eje es una empresa privada, Repsol, que sin embargo tiene su origen en un monopolio público privatizado. A su vez, Repsol había adquirido YPF, otro antiguo monopolio público, en este caso argentino, que también había sido privatizado, pero que vuelve a nacionalizarse por decisión soberana de un gobierno. Se trata de un equilibrio de fuerzas tan delicado entre lo público y lo privado que los jugadores han de ser necesariamente expertos en toda la gama de disciplinas que configuran la diplomacia corporativa: derecho internacional, relaciones internacionales, diplomacia pública, inteligencia, comunicación.

Este papel global de las grandes empresas a menudo choca con el sentimiento proteccionista de los Estados, que desean reservarse el control de los llamados "sectores estratégicos". En España, cuando se produjo la dilatada batalla entre la privatizada Endesa y la italiana Enel (Vélez Álvarez, 2008), que lanzó una OPA hostil sobre la misma, hubo numerosas voces que arguementaron en contra del control extranjero de un sector estratégico español como es el de la energía. Sin embargo, en un espacio con vínculos tan fuertes como la Unión Europea, estas reticencias son cada vez menores. No hay que olvidar que el espacio aéreo alemán está casi totalmente controlado por una empresa española, Indra, o que los principales aeropuertos británicos están en manos de Ferrovial ${ }^{13}$. Estas voces proteccionistas, sin embargo, han llamado la atención sobre el riesgo que supone que determinados sectores estratégicos estén en manos de fondos soberanos provenientes de países del Golfo o de otros Estados emergentes. Un caso paradigmático en este sentido es el interés de los fondos soberanos chinos por los puertos estadounidenses.

No sólo las grandes empresas son jugadoras en este proceso global de toma de decisiones. Las empresas de menor tamaño también pueden ver determinado su futuro en el complejo sistema supranacional en el que, por qué no, también pueden participar. Actualmente, en la Unión Europea hay más de 68 grandes operadores de telefonía móvil. La Comisión Europea desea favorecer un proceso de fusiones que genere un mercado con cuatro o cinco grandes operadores, que serían más competitivos, podrían ofrecer mejores condiciones a los clientes y tendrían mayores posibilidades de consagrar recursos a la $\mathrm{I}+\mathrm{D}+\mathrm{i}$ en una batalla por el desarrollo tecnológico que, hoy por hoy, está perdiendo Europa precisamente a causa de la gran fragmentación del mercado. Es evidente que la Comisión carece de competencias para obligar a 68 compañías mayoritariamente privadas a fusionarse, sólo puede crear las condiciones adecuadas para ello. En este particular dilema del prisionero existen incontables jugadores: las 68 empresas operadores de telefonía móvil, la Comisión, los Gobiernos de los Estados miembros, el propio mercado, los competidores extra europeos... Para obtener resultados ventajosos para sus accionistas, los 68 operadores tendrán que poner a punto sus estrategias de diplomacia corporativa.

No obstante, sería un error centrar la mirada únicamente en Europa y Estados Unidos. Los llamados mercados emergentes generan hoy el mayor número de nuevas empresas transnacionales (Hearing-Smith, 2013). La compañía india Tata, por ejemplo, genera hoy el mayor número de empleos industriales en el Reino Unido, y la china Lenovo adquirió gran parte de IBM en 2005. Las grandes compañías chinas están llevando a cabo la inmensa mayoría de las tareas de construcción de infaestructuras en África, produciendo una sinergia muy positiva que tiene enormes repercusiones políticas. A pesar de sus lazos tradicionales con España, la mayor parte

13 Para profundizar en los logros de las empresas españolas en el mundo, consultar www.marcaespaña.es 
de las obras del plan de desarrollo nacional llamado Horizonte 2020 en Guinea Ecuatorial han sido ejecutadas por la empresa China Dalian o por el conglomerado UNICON, con sede social en Dubai, cuyo CEO es congoleño y cuyo capital está repartido por todo el mundo.

A medida que las compañías procedentes de los mercados emergentes se internacionalizan, será más frecuente que Estados y empresas procedentes de distintos continentes se sienten en la misma mesa de negociación. Igual que ocurre en las grandes conferencias internacionales organizadas por Naciones Unidas, no existe ninguna garantía de que sus representantes compartan valores, cultura u objetivos, por lo cual las erramientas de la diplomacia corporativa serán más importantes que nunca. del éxito de este tipo de interacciones entre actores dispares dependerá el crecimiento económico global del futuro, y por supuesto, el éxito de cada una de esas empresas en el mercado global.

Para la consecución de los objetivos comunes de la sociedad internacional actual, como el desarrollo, la lucha contra la pobreza, la ciber-seguridad, la energía o el cambio climático, el papel de las multinacionales es igual de importante que el de los Estados y las Organizaciones Internacionales.

\section{Conclusiones}

Si en los siglos que transcurrieron entre el faraón Sesotris III y la reina Hatsepsut se dio el salto de la diplomacia puramente comercial a la creación de la figura del comisionado real como antecedente remoto de los embajadores, hoy se está viviendo un proceso inverso. El monopolio que durante siglos han ostentado los diplomáticos tradicionales al servicio del Estado ha terminado.

Como hemos tenido ocasión de comprobar, el fin de este monopolio se extiende a todos los campos de la llamada nueva diplomacia pública. La comunicación pública en materia de relaciones internacionales, que antes se encontraba exclusivamente en manos de los ministerios de asuntos exteriores y de algunos otros órganos públicos privilegiados, hoy se extiende a fundaciones, ONGs o empresas, sin olvidar el papel fundamental que desempeñan los medios de comunicación. La diplomacia cultural, aunque en España sigue definiéndose como un ámbito casi exclusivamente público, camina a pasos agigantados hacia un modelo de coexistencia con el sector privado que pasa por la búsqueda de financiación privada, sin olvidar la relevancia de las ICC. Y es, en fin, en la diplomacia corporativa donde más se aprecia el rol primordial que hoy representan las empresas en el proceso global de toma de decisiones.

En efecto, la sociedad internacional del siglo XXI se caracteriza por el polilateralismo, un modelo de relaciones internacionales donde los nuevos actores, como las Organizaciones Internacionales, las ONGs, las empresas multinacionales, los medios de comunicación, los individuos y un largo etcétera, también practican el ejercicio de las relaciones internacionales, empleando principalmente para ello las herramientas e instrumentos de la diplomacia pública. Surge así una nueva diplomacia pública privada que supone, de hecho, una excelente oportunidad profesional para los especialistas en nuestra disciplina.

\section{El monopolio de los diplomáticos tradicionales al servicio del Estado ha terminado}




\section{Bibliografía}

\section{Libros}

Alberto Pérez, R. (2008). Estrategias de comunicación. Barcelona: Ariel Comunicación.

Clark , A.M. (2001). Diplomacy of Conscience: Amnesty International and changing Human Rights norms. Princeton University Press.

Cull, N. (2009). Public Diplomacy: Lessons from the past. Los Angeles: Figueroa Press.

Hayden, C. (2012). The rhetoric of soft power. Public diplomacy in global contexts. London: Lexington Books.

Kiehl, W. P. (2012). The last three feet. Case Studies in Public Diplomacy. Washington: Public Diplomacy Council.

Melgar Valero, L. (2010). Diplomacia pública: la gestión de la imagen país. Madrid: MAEC.

Millar, D.P. and Heath, R.L. (2003). Responding to crisis: a rhetorical approach to crisis communication. New York: Routledge.

Noya, J. (2010). Diplomacia pública para el siglo XXI. Madrid: Ariel.

Melissen, J. (2005). The new public diplomacy. Soft Power in International Relations. London: Palgrave macmillan.

Reuter, P. (1956). Institutions Internationales. París: Presses Universitaires de France.

Vilariño Pintos, E. (2007). Curso de derecho diplomático y consular. Madrid: Tecnos.

V.AA (2012). Retos de nuestra acción exterior: Diplomacia Pública y Marca España. Madrid: Colección Escuela Diplomática.

Rana, K. S. (2011). 21st century diplomacy: a practitioner's guide. London: Continuum.

\section{Artículos}

Fernández, P. (2012). Valoración de una expropiación: YPF y Repsol en Argentina. IESE, Documento de Investigación.

Galán Allué, J. M. (1995). Aspectos de la diplomacia del Antiguo Egipto. Madrid: CSIC.

Haring-Smith, W. (2013). Diplomatic business: engaging corporations in global policy. GG2022.

Li, S. (2013). Dancin in Davos: combining private sector, government and rising nonstate actors. Exchange diplomacy journal.

Rubin, A. (1989). The case of private diplomacy. The Fletcher Forum.

Szántó, A. (2012). International cultural engagement at a turning point: observations and recommendations from the Salzburg Global Seminar.

Vélez Álvarez, L.G. (2008). La concentración de la industria eléctrica europea. Encuentro Nacional Académico de Regulación, Universidad EAFIT.

Wiseman, G. (1999). Polylateralism and New Models of Global Dialogue. Leicester Diplomatic Studies Programme. 